Original Article

\title{
The effect of postural control and balance on femoral anteversion in children with spastic cerebral palsy
}

\author{
Gul Oznur Karabicak, PT, PhD ${ }^{1)^{*}}$, Nilay Comuk Balci, PT, PhD ${ }^{1)}$, \\ Mustafa Gulsen, PT, PhD ${ }^{2)}$, Basar Ozturk, PT, PhD ${ }^{3)}$, Nuri Cetin, MD ${ }^{4)}$ \\ 1) Department of Physiotherapy and Rehabilitation, Faculty of Health Sciences, Baskent University: \\ Eskisehir Road 20. Km. Baglica, Ankara, Turkey \\ 2) Physiotherapy Program, Vocational School of Health Sciences, Baskent University, Turkey \\ 3) Ergotherapy Department, Faculty of Health Sciences, Biruni University, Turkey \\ 4) Department of Physical Medicine and Rehabilitation, Baskent University Ankara Hospital, Turkey
}

\begin{abstract}
Purpose] The aim of the study was to investigate the relationships between femoral anteversion and functional balance and postural control in children with spastic cerebral palsy. [Subjects and Methods] Twenty children with spastic cerebral palsy (mean age $=12.4 \pm 4.5$ ) with grosss motor functional classification system levels I, II, and III were recruited for this study. Functional balance was evaluated using the Pediatric Balance Scale, postural control was evaluated using the Trunk Control Measurement Scale, and femoral anteversion was assessed with a handheld goniometer using the great trochanter prominence method. [Results] The results indicated that there was significant correlation between femoral anteversion and Trunk Control Measurement Scale dynamic reaching score. There were no significant correlation between femoral anteversion and the Trunk Control Measurement Scale static sitting balance, Trunk Control Measurement Scale selective movement control, total Trunk Control Measurement Scale and Pediatric Balance Scale results. [Conclusion] Increased femoral anteversion has not correlation with functional balance, static sitting, and selective control of the trunk. Femoral anteversion is related to dynamic reaching activities of the trunk, and this may be the result of excessive internal pelvic rotation. It is important for the health professionals to understand that increased femoral anteversion needs to be corrected because in addition to leading to femoral internal rotation during walking, it also effects dynamic reaching activities of spastic children with cerebral palsy.

Key words: Cerebral palsy, Postural control, Femoral anteversion
\end{abstract}

(This article was submitted Jan. 12, 2016, and was accepted Feb. 15, 2016)

\section{INTRODUCTION}

Cerebral palsy $(\mathrm{CP})$ can be basically defined as a group of disorders of the movement and posture, causing activity limitation, that are attributed to nonprogressive deficits that takes place in the immature brain. The motor disorders of cerebral palsy are often accompanied by deficits in sensation, cognition, communication, perception, and/or behavior, and/or by seizure disorder ${ }^{1)}$. While the primary deficit is nonprogressive, motor impairment, muscle tone ${ }^{2)}$, postural disorders ${ }^{3)}$, spinal deformities ${ }^{4)}$, and inactivity due to foot deformities ${ }^{5}$ cause the disability to be progresive ${ }^{6}$. $\mathrm{CP}$ exhibits motor disability that has a resultant effects on biomechanics of the body. Motor disorders of children with CP are related to primary deficits (such as spasticity, muscle weakness, reduced coordination, and a loss of selective motor control) and secondary deficits (such as muscle contracture and bone deformities $)^{7}$. The prevelance of CP in many societies has been reported to be on average of $2-3$

*Corresponding author. Gul Oznur Karabicak (E-mail: guloznur@gmail.com)

(C2016 The Society of Physical Therapy Science. Published by IPEC Inc.

This is an open-access article distributed under the terms of the Creative Commons Attribution Non-Commercial No Derivatives (by-nc-nd) License $<$ http://creativecommons.org/licenses/by-nc-nd/4.0/>. 
per 1,000 live births ${ }^{8,9)}$. There are studies reporting an average of 4.4 per 1,000 births in the Turkish popuation ${ }^{10)}$.

Postural control is another main problem in children with CP that causes limitations in daily life activities and is a major component of gait disorder. Also, postural control and posture plays a key role in correct upright posture and spinal orientation $^{11)}$. In order to explain factors related to gait disorders and guide treatment, identification of those children with impaired standing balance is vital ${ }^{12-14)}$. Postural control and balance reactions are insufficient in children with cerebral palsy, and these children use an altered patterns of muscle coordination, which are tought to be a result of two interacting mechanisms, the primary deficit due to early brain damage and compensation due to postural instability ${ }^{13)}$. Studies show that limitations with respect to balance and walking in children with CP may lead to several deformities including lower extremity and these deformities can be treated though training ${ }^{14)}$. Also, a number of assessment tools are utilized in a holistic approach to evaluate the mobility, balance, and functional ability of children with $\left.\mathrm{CP}^{15}, 16\right)$.

Another important deficit frequently seen in children with cerebral palsy is femoral anteversion (FA). The FA angle of the femur can be defined as a measure of the rotation of the neck of the femur around the diaphysis. The FA angle is $30^{\circ}$ in normal development, and it decreases to $15^{\circ}$ as the skeletal system matures. FA is increased slightly and maintained at a high level during development in children with $\mathrm{CP}^{17)}$. In ambulatory patients, excessive $\mathrm{FA}$ is thought to place the hip abductor muscles at a biomechanical disadvantage during gait by decreasing the functional lever arm relative to the hip joint center during the stance phase ${ }^{18)}$. Increased FA is defined as a structural deformity that could affect the adjusted foot progression angle ${ }^{19)}$, and recent studies have reported it as a cause of gait abnormalities ${ }^{20)}$, and lower extremity deformities ${ }^{19}$.

Even though there have been several studies focussed on the importance of postural control and balance in children with $\mathrm{CP}$, the relationship between FA angle and postural control is still a question. Therefore, the main aim of this study was to detect the relationships between FA and two areas which peaople with CP often experience problems. The relationship between FA and functional balance and postural control.

\section{SUBJECTS AND METHODS}

Twenty children with CP were recruited for this study from a Baskent University, Department of Physical Medicine and Rehabilitation outpatient clinic. Inclusion criteria were as follows: a) spastic CP diagnosis (for spastic hemiplegic CP, only right hemiplegic children), b) between 5 and 18 years of age, and c) Gross Motor Functional classification of Level I, II or III; Exclusion criteria were as follows: a) administration of botulinum toxin-A by injection or surgery within the last 6 months, b) other musculoskeletal, cardiovascular, or neurologic disorders, or c) incompatible degree of comprehension and cooperation for performance of the activities proposed. At the beginning of the study, the parents of the children were informed about the research study and signed an informed consent form stating that they and their children would participate voluntarily. The study was approved by the Baskent University ethics committee for noninterventional clinical trials.

Functional classification of CP was performed using the Gross Motor Function Classification System (GMFCS). The GMFCS represents a functional classification of children with CP, that aims to determine the level of a child based on the child's abilities and limitations to perform gross motor function activities. Children are classified according with five levels as follows: level I represents the ability to walk without limitations, level II representes the ability to walk with limitations, level III represents the ability to walk using a handheld mobility device; level IV represents self-mobility with limitations, and level $\mathrm{V}$ represents the requirement to be transported in a manual wheelchair ${ }^{21)}$.

Functional balance was evaluated using the Pediatric Balance Scale (PBS). The PBS examines functional balance using 14 tasks, with score ranging from 0 to 56, higher scores indicating better postural control. The tasks evaluated in the PBS are as follows: (1) sit to standing, (2) standing to sitting, (3) transfers, (4) standing unsupported, (5) sitting unsupported, (6) standing with eyes closed, (7) standing with feet together, (8) standing with one foot in front, (9) standing on one foot; (10) turning 360 degrees, (11) turning to look behind, (12) retrieving object from floor, (13) placing alternate foot on stool, and (14) reaching forward with outstretched $\operatorname{arm}^{22}$.

Postural control was evaluated based on trunk control while sitting with the Trunk Control Measurement Scale (TCMS). This recently developed scale consists of three subscales (15 items in total) measuring both static and dynamic aspects of trunk control, with the "trunk" including the thorax and the pelvis. The first subscale, static sitting balance, evaluates the ability of the child to maintain a stable trunk position during upper and lower limb movements. The second subscale, selective movement control, evaluates the performance of selective trunk movements within the base of support in three planes: the sagittal (flexion/extension), frontal (lateral bending), and transverse planes (rotation). The third subscale, dynamic reaching, assesses the performance during three reaching tasks requiring active trunk movements beyond the base of support. For test administration, children were seated on a table or bench without back, arm, or foot support. No orthoses or shoes were worn during testing. The best of three performances for each item was considered for scoring. The TCMS total score ranges from 0 to 58 , with a higher score indicating a better performance. Item scores for each subscale were summed, resulting in three subscale scores, and summing these subscale scores resulted in a total TCMS score ${ }^{23,24)}$. There is a standard testing procedure with respect to the positioning of the subjects. Therefore, the children's sitting position is already standardized.

The FA angle was measured using the great trochanter prominence method as described by Netter and confirmed by Ruwe et $\mathrm{al}^{25)}$. The FA was measured in the prone position, with the knee flexed at 90 degrees and the tibial segment inclined laterally toward the table. The physician stood on the opposite side for assessment. The great trochanter was palpated until it was at its 
most prominent position, and the angle formed by the long axis of the tibial and vertical segments, that is the FA angle was measured with a long-arm goniometer. An FA>30 degrees was considered excessive. The right leg was selected for statistical independence, and the data for the right leg were used for the analysis.

The sample size was determined based on statistical power analysis procedures using the PASS 2005 software (NCSS, Kaysville, UT, USA). The power analysis indicated that 20 participants were needed with $90 \%$ power and a $5 \%$ type 1 error. The power analysis of our study showed a power of $80 \%$ with the PBS as the primary outcome.

The IBM SPSS Statistics, Version 20.0, software (released 2011, IBM Corp., Armonk, NY, USA) was used for calculations. All values were presented as the mean \pm standard deviation and frequencies. Spearman's correlation was used to compare the test results. The alpha level for all statistical analyses was set a priori at $\mathrm{p}<0.05$. The strength of relationships was described as detailed by Leslie et al., with $0.00-0.25=$ little or no relationship, $0.26-0.50=$ fair degree of relationship, $0.51-0.75=$ moderate to good relationship, and $0.76-1.00=\operatorname{good}$ to excellent relationship ${ }^{26)}$.

\section{RESULTS}

Demographic and clinical characteristics of the patients are shown in Table 1. In the correlation analysis, a statistically significant fairly positively correlation was detected between FA and the TCMS dynamic reaching score $(p<0.05)$. There were no significant correlation between FA and TCMS-static sitting balance, TCMS-selective movement control, Total TCMS and PBS results $(\mathrm{p}>0.05)$ (Table 2).

\section{DISCUSSION}

Torsional disorders are frequent in spastic children with CP. Identification of these anomalies is essential because they modify the length of leverage and create abnormal moments ${ }^{27}$. These condition effect gait parameters and the gait type of children, and they also affect their daily living activities. The purpose of the current study was to explore the effect of excessive FA on balance and postural control parameters of children with spastic CP. This study delineates the relationship between FA and dynamic reaching, and there was no correlation of FA with functional balance, selective movement of the trunk, and and static sitting balance.

Postural control is fundamental to efficient functional performance in all activities of daily living. This complex process depends on the interaction of the visual, vestibular, and peripheral systems, commands of the central nervous system, and neuromuscular response. Deficits in postural control due to motor impairment have been identified as one of the main limitations in the development of children with $\mathrm{CP}^{12,28)}$. Postural control in the sitting position can be used to assess spinal

Table 1. Demographic and physical properties of the children with spastic $\mathrm{CP}$

\begin{tabular}{|c|c|c|}
\hline & & Mean \pm SD \\
\hline \multicolumn{2}{|l|}{ Age (years) } & $12.3 \pm 4.5$ \\
\hline \multicolumn{2}{|c|}{ Gestational age (weeks) } & $38.5 \pm 2.4$ \\
\hline \multicolumn{2}{|c|}{ Maternal age (years) } & $39.0 \pm 7.2$ \\
\hline \multicolumn{2}{|c|}{ Paternal age (years) } & $41.2 \pm 6.7$ \\
\hline \multicolumn{2}{|c|}{ Height $(\mathrm{cm})$} & $117.6 \pm 21.8$ \\
\hline \multicolumn{2}{|l|}{ Weight (kg) } & $22.6 \pm 11.3$ \\
\hline & & $\mathrm{n}(\%)$ \\
\hline \multirow[t]{3}{*}{ Gender } & Girl & $8(40)$ \\
\hline & Boy & $12(60)$ \\
\hline & Diplegia & $6(30)$ \\
\hline \multirow{4}{*}{$\begin{array}{l}\text { Topographical } \\
\text { classification }\end{array}$} & Quadriplegia & $4(20)$ \\
\hline & Hemiplegia & $9(45)$ \\
\hline & Triplegia & $1(5)$ \\
\hline & Level I & $1(50)$ \\
\hline \multirow[t]{3}{*}{ GMFCS } & Level II & $6(30)$ \\
\hline & Level III & $4(20)$ \\
\hline & $\begin{array}{c}\text { Positive } \\
\mathrm{n}(\%)\end{array}$ & $\begin{array}{c}\text { Negative } \\
\mathrm{n}(\%)\end{array}$ \\
\hline $\begin{array}{l}\text { Children with } \\
\text { excessive FA }\end{array}$ & $15(75)$ & $5(25)$ \\
\hline
\end{tabular}

Table 2. Correlation of femoral anteversion with the PBS and TCMS

\begin{tabular}{lcc}
\hline & & FA \\
& Mean \pm SD & r \\
\hline TCMS - static sitting balance & $16.1 \pm 3.7$ & 0.071 \\
TCMS - selective movement control & $17.8 \pm 5.7$ & 0.262 \\
TCMS - dynamic reaching & $7.4 \pm 1.7$ & $0.462 *$ \\
Total TCMS & $41.2 \pm 9.6$ & 0.281 \\
PBS & $40.7 \pm 14.6$ & 0.254 \\
\hline
\end{tabular}

$* \mathrm{p}<0.05$. TCMS: Trunk Control Measurement Scale; PBS: Pediatric Balance System 
instability, trunk muscle weakness, and activities of daily living impairments in cerebral palsy ${ }^{26)}$.

The ability to balance the trunk in human activities, in order to straighten posture, is an important ability because it improves stability. In children with cerebral palsy, control and stability of the trunk are low, and this results in poor balance ability $\left.{ }^{27}, 29\right)$. The dynamic reaching challenge item in TCMS is an aspect of dynamic trunk control, i.e., the ability to actively move the trunk beyond the stability limits of the base of support during three reaching tasks, requiring forward, lateral, and a combination of rotation and lateral displacement of the trunk. In a previous study, performance of lateral trunk displacement was already difficult for children with $\mathrm{CP}$, and difficulties were found when executing an additional rotation of the trunk during crossed reaching ${ }^{24)}$. Executing trunk rotations while reaching makes postural control in children with CP more challenging and consequently hampers their reaching performance, as shown in previous research ${ }^{30,31)}$.

Heyrman et al. ${ }^{32)}$ assessed whether altered trunk movements during gait in children with spastic diplegia were caused by either compensatory movements or underlying trunk deficits. The results of their study showed that increased altered trunk movements during gait were related to lower performance on the TCMS when sitting. This finding may be considered consistent with our findings showing that the dynamic reach functions of the trunk were related to excessive FA in the lower extremities of the spastic CP children. Sæther et al. ${ }^{33)}$ also found that trunk control when sitting as assessed with trunk measurement scales, had a moderate to good correlation with trunk control during gait cycle. Taken together, this indicates that trunk control affects gait features in children with CP.

Spastic diplegic children are also characterized by gluteus medius weakness, and to keep the lever arm as long as possible, they have to move the femoral neck into a more frontal plane. Indeed, excessive FA should be compensated for by internal hip rotation that places the femoral neck into a frontal plane and increases the gluteus medius lever arm length. The possible means of achieving this goal include internal pelvic rotation on one hand and internal hip rotation rotation on the other. If pelvic internal rotation is too excessive, the femoral neck would be oriented inward so that the hip can compensate for it with external rotation to place the femoral neck into a strictly frontal plane. If internal hip rotation is too excessive, the femoral neck would also be oriented inward, which could externally rotate the pelvis ${ }^{34)}$. These assumptions follow the theory of a compensatory mechanism between the hip and pelvis advocated by DeLuca et al. ${ }^{35)}$ and Saraph et al. ${ }^{36)}$ and corresponded to the tertiary deformity described by Gage ${ }^{27)}$. Rethlefsen et al. ${ }^{37)}$ showed that the causes of intoeing gait are also multiple. In their study, the most frequent causes were internal hip rotation, internal pelvic rotation, and internal tibial rotation. Internal pelvic rotation was observed in $32 \%$ of their cases. DeLuca et al. ${ }^{35)}$ demonstrated that pelvic rotation should be considered in surgical decision making: Of the 67 limbs for which femoral derotational osteotomy was indicated on the basis of physical examination, 19 were not operated because 3D gait analysis determined the cause to be internal pelvic rotation. This knowledge also supports our findings that femoral anteversion has a relationship with dynamic reaching movements of the trunk that require pelvic girdle muscle activation. The standing posture is controlled by the ankle, knee, and hip joints. However, in the sitting posture, no positional adjustment occurs ${ }^{28}$. This condition also explains why femoral anteversion had no correlation with the PBS but was correlated with dynamic functions of the trunk in our study.

In conclusion, the present study showed that increased FA has not correlation with functional balance, static sitting, and selective control of the trunk. FA is related to dynamic reaching activities of the trunk, and this may be the result of excessive internal pelvic rotation. Further studies should be conducted to investigate the effect of internal pelvic rotation on functional balance and postural control in spastic CP. It is important for the health professionals to understand that increased femoral anteversion needs to be corrected because in addition to it leading to femoral internal rotation during walking, it also effects dynamic reaching activities of the spastic children with CP. A limitation of this study is the lack of a control group. Further studies should be performed to compare tests in children with different types of CP.

\section{REFERENCES}

1) Bax M, Goldstein M, Rosenbaum P, et al. Executive Committee for the Definition of Cerebral Palsy: Proposed definition and classification of cerebral palsy, April 2005. Dev Med Child Neurol, 2005, 47: 571-576. [CrossRef] [Medline]

2) Matthews DJ, Balaban B: [Management of spasticity in children with cerebral palsy]. Acta Orthop Traumatol Turc, 2009, 43: 81-86. [CrossRef] [Medline]

3) Macias ML: Abnormal sitting postures in children with neuromotor disabilities and use of the pelvic corset or molded seat for adaptative sitting. Pediatr Phys Ther, 1998, 10: 74-77. [CrossRef]

4) Imrie MN, Yaszay B: Management of spinal deformity in cerebral palsy. Orthop Clin North Am, 2010, 41: 531-547. [CrossRef] [Medline]

5) Sees JP, Miller F: Overview of foot deformity management in children with cerebral palsy. J Child Orthop, 2013, 7: 373-377. [CrossRef] [Medline]

6) Montero Mendoza S, Gómez-Conesa A, Hidalgo Montesinos MD: Association between gross motor function and postural control in sitting in children with Cerebral Palsy: a correlational study in Spain. BMC Pediatr, 2015, 15: 124. [CrossRef] [Medline]

7) Kim CJ, Son SM: Comparison of spatiotemporal gait parameters between children with normal development and children with diplegic cerebral palsy. J Phys Ther Sci, 2014, 26: 1317-1319. [CrossRef] [Medline]

8) Himpens E, Van den Broeck C, Oostra A, et al.: Prevalence, type, distribution, and severity of cerebral palsy in relation to gestational age: a meta-analytic review. Dev Med Child Neurol, 2008, 50: 334-340. [CrossRef] [Medline]

9) Oskoui M, Coutinho F, Dykeman J, et al.: An update on the prevalence of cerebral palsy: a systematic review and meta-analysis. Dev Med Child Neurol, 2013, 55: 509-519. [CrossRef] [Medline]

10) Serdaroğlu A, Cansu A, Ozkan S, et al.: Prevalence of cerebral palsy in Turkish children between the ages of 2 and 16 years. Dev Med Child Neurol, 2006, 48: 
413-416. [CrossRef] [Medline]

11) Hazar Z, Karabicak GO, Tiftikci U: Reliability of photographic posture analysis of adolescents. J Phys Ther Sci, 2015, 27: 3123-3126. [CrossRef] [Medline]

12) Rose J, Wolff DR, Jones VK, et al.: Postural balance in children with cerebral palsy. Dev Med Child Neurol, 2002, 44: 58-63. [CrossRef] [Medline]

13) Brogren E, Hadders-Algra M, Forssberg H: Postural control in sitting children with cerebral palsy. Neurosci Biobehav Rev, 1998, 22: 591-596. [CrossRef] [Medline]

14) Woollacott MH, Shumway-Cook A: Postural dysfunction during standing and walking in children with cerebral palsy: what are the underlying problems and what new therapies might improve balance? Neural Plast, 2005, 12: 211-219, discussion 263-272. [CrossRef] [Medline]

15) Besios T, Nikolaos A, Vassilios G, et al.: Comparative reliability of the PEDI, GMFM and TUG tests for children with cerebral palsy. J Phys Ther Sci, 2013, 25: 73-76. [CrossRef]

16) Lim H: Correlation between the selective control assessment of lower extremity and pediatric balance scale scores in children with spastic cerebral palsy. J Phys Ther Sci, 2015, 27: 3645-3649. [Medline] [CrossRef]

17) Shefelbine SJ, Carter DR: Mechanobiological predictions of femoral anteversion in cerebral palsy. Ann Biomed Eng, 2004, 32: 297-305. [Medline] [CrossRef]

18) Riccio AI, Carney CD, Hammel LC, et al.: Three-dimensional computed tomography for determination of femoral anteversion in a cerebral palsy model. J Pediatr Orthop, 2015, 35: 167-171. [CrossRef] [Medline]

19) Lee KM, Chung CY, Sung KH, et al.: Femoral anteversion and tibial torsion only explain $25 \%$ of variance in regression analysis of foot progression angle in children with diplegic cerebral palsy. J Neuroeng Rehabil, 2013.

20) Akalan NE, Temelli Y, Kuchimov S: Discrimination of abnormal gait parameters due to increased femoral anteversion from other effects in cerebral palsy. Hip Int, 2013, 23: 492-499. [CrossRef] [Medline]

21) Palisano RJ, Rosenbaum P, Bartlett D, et al.: Content validity of the expanded and revised Gross Motor Function Classification System. Dev Med Child Neurol, 2008, 50: 744-750. [CrossRef] [Medline]

22) Franjoine MR, Gunther JS, Taylor MJ: Pediatric balance scale: a modified version of the berg balance scale for the school-age child with mild to moderate motor impairment. Pediatr Phys Ther, 2003, 15: 114-128. [CrossRef] [Medline]

23) Heyrman L, Molenaers G, Desloovere K, et al.: A clinical tool to measure trunk control in children with cerebral palsy: the Trunk Control Measurement Scale. Res Dev Disabil, 2011, 32: 2624-2635. [CrossRef] [Medline]

24) Heyrman L, Desloovere K, Molenaers G, et al.: Clinical characteristics of impaired trunk control in children with spastic cerebral palsy. Res Dev Disabil, 2013, 34: 327-334. [CrossRef] [Medline]

25) Ruwe PA, Gage JR, Ozonoff MB, et al.: Clinical determination of femoral anteversion. A comparison with established techniques. J Bone Joint Surg Am, 1992, 74: 820-830. [Medline]

26) Jeong J, Park DS, Lee H, et al.: A reliability of the prototype trunk training system for sitting balance. J Phys Ther Sci, 2014, 26: 1745-1747. [Medline] [CrossRef]

27) Gage JR: Gait analysis. An essential tool in the treatment of cerebral palsy. Clin Orthop Relat Res, 1993, (288): 126-134. [Medline]

28) Duarte NA, Grecco LA, Franco RC, et al.: Correlation between Pediatric Balance Scale and functional test in children with cerebral palsy. J Phys Ther Sci, 2014, 26: 849-853. [CrossRef] [Medline]

29) Quinby JM, Abraham A: Musculoskeletal problems in cerebral palsy. Curr Paediatr, 2005, 15: 9-14. [CrossRef]

30) Ju YH, Hwang IS, Cherng RJ: Postural adjustment of children with spastic diplegic cerebral palsy during seated hand reaching in different directions. Arch Phys Med Rehabil, 2012, 93: 471-479. [CrossRef] [Medline]

31) Ju YH, You JY, Cherng RJ: Effect of task constraint on reaching performance in children with spastic diplegic cerebral palsy. Res Dev Disabil, 2010, 31: 1076-1082. [CrossRef] [Medline]

32) Heyrman L, Feys H, Molenaers G, et al.: Altered trunk movements during gait in children with spastic diplegia: compensatory or underlying trunk control deficit? Res Dev Disabil, 2014, 35: 2044-2052. [CrossRef] [Medline]

33) Sæther R, Helbostad JL, Adde L, et al.: The relationship between trunk control in sitting and during gait in children and adolescents with cerebral palsy. Dev Med Child Neurol, 2015, 57: 344-350. [Medline] [CrossRef]

34) Simon AL Jr, Presedo A, Ilharreborde B, et al.: Can turned inward patella predict an excess of femoral anteversion during gait in spastic diplegic children? J Pediatr Orthop, 2014, 34: 405-410. [CrossRef] [Medline]

35) DeLuca PA, Davis RB 3rd, Ounpuu S, et al.: Alterations in surgical decision making in patients with cerebral palsy based on three-dimensional gait analysis. J Pediatr Orthop, 1997, 17: 608-614. [CrossRef] [Medline]

36) Saraph V, Zwick EB, Zwick G, et al.: Effect of derotation osteotomy of the femur on hip and pelvis rotations in hemiplegic and diplegic children. J Pediatr Orthop B, 2002, 11: 159-166. [Medline]

37) Rethlefsen SA, Healy BS, Wren TA, et al.: Causes of intoeing gait in children with cerebral palsy. J Bone Joint Surg Am, 2006, 88: 2175-2180. [CrossRef] [Medline] 